\title{
FASCITIS NECROTIZANTE POR STREPTOCOCCUS PYOGENES: A PROPÓSITO DE UN CASO
}

\section{NECROTIZING FASCIITIS CAUSED BY STREPTOCOCCUS PYOGENES: A CASE REPORT}

Fumis $M A^{1}$, Bidabehere $\mathrm{MB}^{2}$, Moyano $\mathrm{Y}^{3}$, Sardoy $\mathrm{A}^{4}$, Gubiani $\mathrm{ML}^{5}$, Boldrini $\mathrm{MP}^{6}$, Pinardi $\mathrm{B}^{7}$.

\section{Resumen:}

La fascitis necrotizante por estrepotococo del grupo A es una infección infrecuente del tejido subcutáneo y de la fascia, con una tasa de mortalidad elevada debido a su rápida progresión a shock y fallo multiorgánico. Se desarrolla generalmente en extremidades tras un traumatismo o lesión previa. El diagnóstico temprano es esencial así como también el manejo rápido y agresivo. Presentamos un caso de fascitis necrotizante de evolución rápida a pesar del diagnóstico precoz y tratamiento específico instaurado.

Palabras clave: fascitis necrotizante; Streptococcus pyogenes; síndrome de shock tóxico

\section{Abstract:}

Necrotizing fasciitis caused by group A Streptococcus is an uncommon infection of the subcutaneous tissue and fascia, with a high mortality rate due to its rapid progression to shock and multiorgan failure. It usually develops in extremities after trauma or previous injury. Early diagnosis is essential as well as fast and aggressive management. We present a case of rapidly evolving necrotizing fasciitis despite the early diagnosis and specific treatment established.

Keywords: Intestinal diseases parasitic; enterobiasis; appendicitis

\footnotetext{
${ }^{1}$ Residente de segundo año de Dermatología. Email de contacto: agusfumis@hotmail.com

${ }^{2}$ Residente de tercer año de Dermatología.

${ }^{3}$ Residente de tercer año de Dermatología.

${ }^{4}$ Residente de primer año de Dermatología.

${ }^{5}$ Médica dermatóloga, Instructora Docente.

${ }^{6}$ Médica dermatóloga, Instructora Docente.

${ }^{7}$ Médica dermatóloga, Jefa del Servicio de Dermatología, Hospital San Roque.
} 


\section{Introducción}

El Streptococcus pyogenes o Estreptococo betahemolítico del grupo A (EGA) produce un amplio espectro de infecciones, dentro de ellas encontramos las denominadas infecciones invasivas, las cuales están asociadas con el aislamiento de EGA en un medio habitualmente estéril, incluyendo la fascitis necrotizante. ${ }^{1,2}$ La fascitis necrotizante es una enfermedad infecciosa rápidamente progresiva de los tejidos blandos, que afecta piel, tejido celular subcutáneo, fascia superficial y en ocasiones fascia profunda y músculos. ${ }^{2}$ Una de las complicaciones más severas es el Síndrome de Shock Tóxico Estreptocócio (SSTE), definido por la presencia de una infección invasiva por EGA asociada a shock y fallo multiorgánico, presentando una tasa de mortalidad que oscila entre el $30 \%$ y el $70 \%$ de los casos. ${ }^{1,2}$

\section{Caso clínico}

Paciente femenino de 57 años de edad, con antecedentes patológicos de obesidad, hipertensión y asma. Ingresa al servicio de guardia central por disnea clase funcional IV, vómitos, fiebre, eritema y dolor en miembro inferior izquierdo de 72 horas de evolución. Al momento del ingreso se constata: hipotensión (80/40 $\mathrm{mmHg}$ ), taquicardia (142 lat/min), taquipnea (32 respiraciones $/ \mathrm{min}$ ), hipertermia $\left(38,5^{\circ} \mathrm{C}\right)$, saturación de oxigeno $90 \%$ aire ambiente. Se realizó interconsulta con Servicio de Dermatología. Al examen físico se observó placa eritematoviolácea, de bordes poco definidos, con flictenas en superficie, una de las cuales drenaba espontáneamente secreción hemática, localizada en miembro inferior izquierdo. Conjuntamente presentó edema y aumento de temperatura local.

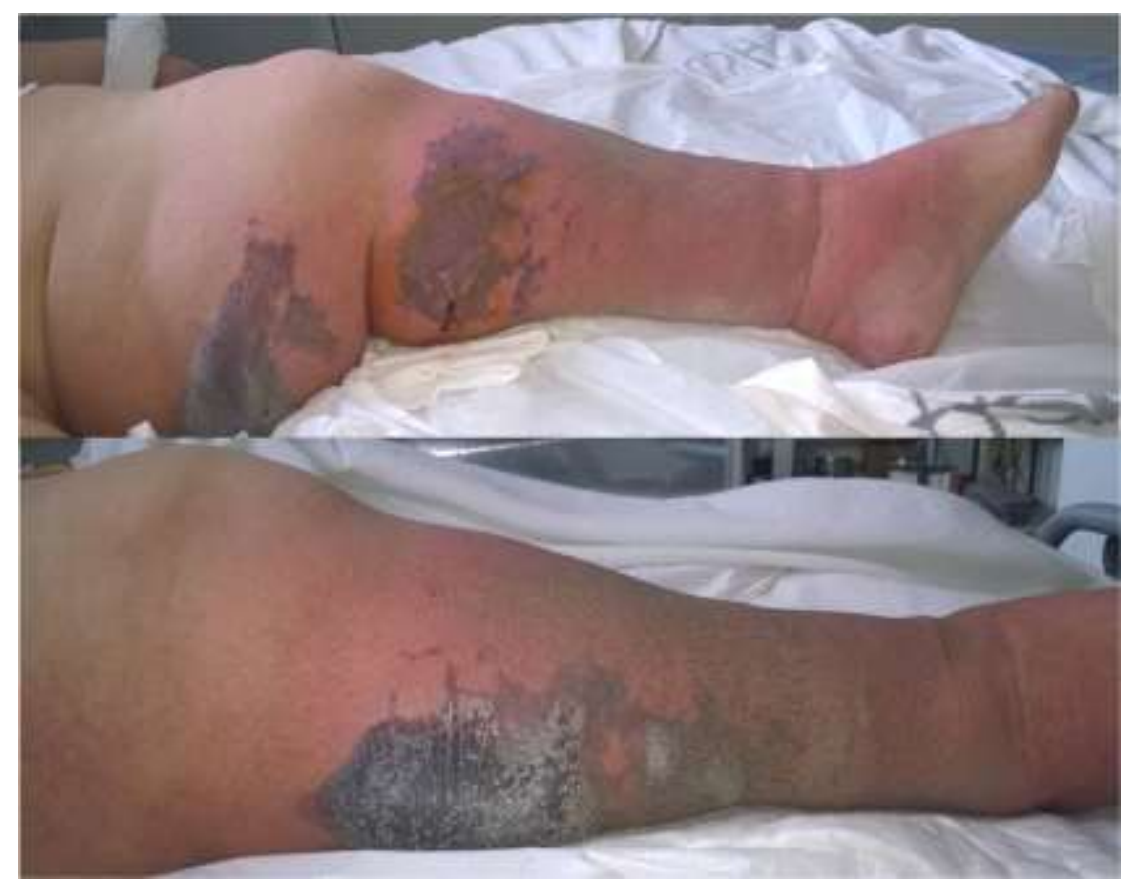

Imagen 1. Placa eritematoviolácea con flictenas en superficie localizadas en cara interna y externa de miembro inferior izquierdo. 
Se solicitó laboratorio que informó anemia (hemoglobina $11 \%$, hematocrito $34 \%$ ); leucocitosis con neutrofilia (glóbulos blancos 18.70 miles $/ \mathrm{mm}^{3}$, neutrófilos 98\%); eritrosedimentación elevada 37 $\mathrm{mm} / 1^{\circ}$ hora; alteración de la función renal (urea $109 \mathrm{mg} / \mathrm{dl}$, creatinina 3.60 $\mathrm{mg} / \mathrm{dl})$; hiponatremia (133 $\mathrm{mEq} / \mathrm{l})$, hipocalcemia $\quad(6.40 \quad \mathrm{mg} / \mathrm{dl})$; hipomagnesemia $\quad(1.19 \mathrm{mg} / \mathrm{dl})$ aumento de la fosfatasa alcalina (120 $\mathrm{U} / \mathrm{L})$; acidosis metabólica $(\mathrm{pH} 7.24$ $\mathrm{HCO}_{3} 17.60 \mathrm{mEq} / \mathrm{l}$ ); hipoalbuminemia $(1.80 \mathrm{~g} \%)$, hipoglobulinemia $(4.37 \mathrm{~g} \%)$ y disminución en la relación albumina/globulinas (0.41). CPK dentro de parámetros normales. Radiografía de tórax sin particularidades. Se solicitó hemocultivo donde se informó desarrollo de Streptococcus pyogenes.

La paciente fue admitida en la unidad de cuidados intensivos, para soporte hemodinámico con vasopresores $\mathrm{y}$ asistencia respiratoria mecánica. Se inició tratamiento con penicilina $3.000 .000 \mathrm{UI}$ cada 4 horas $\mathrm{y}$ clindamicina $600 \mathrm{mg}$ cada 6 horas. Se realizó desbridamiento quirúrgico, evidenciándose necrosis del tejido celular subcutáneo y fascia. Se recolectaron muestras para cultivo y antibiograma, siendo los resultados negativos debido a la antibioticoterapia previa.

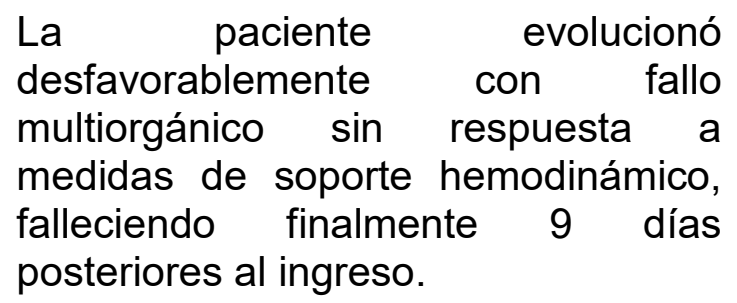

\section{Comentario}

El término fascitis necrotizante se usó por primera vez en la década de 1950, y consiste en la inflamación severa de la vaina muscular que origina trombosis y necrosis del tejido subcutáneo y de la fascia adyacente. 3

Se clasifica en dos tipos basado en los cultivos microbiológicos; la tipo 1 es una infección polimicrobiana causada por microorganismos aerobios y anaerobios que afecta a pacientes inmunocomprometidos $y$ suele aparecer en miembros inferiores, pared abdominal, periné o cerca de heridas quirúrgicas. La tipo 2 es causada por una infección monomicrobiana, por lo general por estreptococo del grupo A, usualmente afecta a pacientes sanos y es una enfermedad rápidamente progresiva. 4,5

La fascitis necrotizante por estreptococo $\beta$ hemolítico del grupo $A$ tiene una incidencia de 0.4 entre 100.000 habitantes y en el $80 \%$ de los casos se adquiere en la comunidad. Se presenta en una edad promedio de 58 años, sin mostrar evidencia significativa en la prevalencia entre hombres y mujeres. ${ }^{3}$

Los mecanismos virulentos del estreptococo incluyen proteínas unidas a la pared celular, proteasas, exotoxinas y súper-antígenos, que activan los linfocitos T-helper produciendo liberación de citoquinas (factor de necrosis tumoral, interleuquina $1 \beta$, interleuquina 2 e interferon), factores de la coagulación 
y factores del complemento promoviendo la necrosis generalizada de la fascia superficial y profunda. Esto produce una infección grave con oclusión vascular, daño neural e isquemia y explica el mecanismo de desarrollo del shock y fallo multiorgánico que se produce en el SSTE.

El cuadro clínico inicia con dolor desproporcionado frente a la aparición de la infección cutánea, habitualmente secundaria a una pequeña herida o traumatismo previo. Otro signo local habitual es el edema indurado que se extiende más allá del área de eritema. La presencia de cambios cutáneos debidos a trombosis de vasos subcutáneos suele producirse posteriormente, produciendo una piel brillante y tensa, que evoluciona a púrpura y grisácea, frecuentemente asociada a la formación de bullas de contenido serosanguinolento.

Entre las manifestaciones sistémicas los pacientes pueden presentar fiebre, deshidratación, confusión y taquicardia. Los hallazgos de laboratorio pueden mostrar leucocitosis con neutrofilia y la presencia de valores elevados de CPK que sugieren una infección profunda de tejidos blandos. Hay bacteriemia documentada en aproximadamente dos tercios de los pacientes, los cuales a menudo desarrollan síndrome de shock tóxico estreptocócico. ${ }^{3,4,8}$
Los estudios de imágenes pueden ser de utilidad para confirmar el diagnóstico, determinar la extensión y la importancia de la afectación.

Los criterios histológicos característicos son la necrosis de la fascia superficial con infiltrados de polimorfonucleares y necrosis fibrinoide de las paredes arteriales y venosas con oclusión trombótica de los vasos. ${ }^{9}$

El diagnóstico es eminentemente clínico junto a un alto índice de sospecha, sumado a otros hallazgos como los resultados de laboratorio, imágenes e histopatología.

Se describen los criterios para el diagnóstico de fascitis necrotizante y SSTE en la Tabla 1. ${ }^{10,11}$ 


\section{Tabla 1. Definición de caso para fascitis necrotizante y síndrome de shock tóxico estreptocócico.

\section{Fasctitis necrotizante}

\section{A. Caso definido}

1. Necrosis de tejidos blandos con afectación de la fascia MÁS

2. Enfermedad sistémica severa

a) Muerte

b) Shock (presión sistólica $<90 \mathrm{~mm} \mathrm{Hg}$ )

c) Coagulopatía intravascular diseminada

d) Disfunción orgánica:

distrés respiratorio agudo

falla renal

hepatopatia

3. Aislamiento de Stretpococcus del grupo A de un sitio normalmente estéril

B. Caso sospechado

1. 1+2 y confirmación serológica de infección por estreptococo del grupo A por un aumento de cuatro veces:

a) Estreptolisina $\mathrm{O}$

b) DNAasa B

2. 1+2 y confirmación histológica: cocos Gram positivos en una infección necrótica de tejidos blandos

\section{Síndrome de shock tóxico estreptocócico}
A. Aislamiento de Streptococcus del grupo A
1. De un sitio estéril
2. De un sitio no estéril
B. Signos clínicos de severidad
1. Hipotensión

2. Anormalidades clínicas y de laboratorio (2 o más de los siguientes):

a) Insuficiencia renal

b) Coagulopatía

c) Afectación hepática

d) Síndrome de distrés respiratorio agudo

Necrosis extensiva de tejidos

e)

rash eritematoso

Caso definitivo: $\mathrm{A} 1+\mathrm{B}(1+2)$

Caso probable: $\mathrm{A} 2+\mathrm{B}(1+2)$ 
Los diagnósticos diferenciales se realizaran con lesiones isquémicas acras, erupciones eritematopapulosas graves y con las demás infecciones necrosantes de los tejidos blandos. ${ }^{12}$ (Tabla 2 )

\begin{tabular}{|c|c|c|}
\hline $\begin{array}{l}\text { Lesiones } \\
\text { isquémicas } \\
\text { acras }\end{array}$ & Erupciones eritematopapulosas & $\begin{array}{l}\text { Lesiones } \\
\text { eritematonecróticas o } \\
\text { necróticas de causas } \\
\text { infecciosas }\end{array}$ \\
\hline $\begin{array}{l}\text { Trombocitopenia } \\
\text { por heparina }\end{array}$ & Síndrome de shock tóxico estafilocócico & Miositis o piomiositis \\
\hline $\begin{array}{c}\text { Trombosis } \\
\text { venosa profunda }\end{array}$ & Síndrome de shock tóxico estreptocócico & Mionecrosis no clostridial \\
\hline $\begin{array}{l}\text { Aterosclerosis } \\
\text { obliterante }\end{array}$ & Escarlatina grave & $\begin{array}{l}\text { Gangrena gaseosa por } \\
\text { Clostridium spp }\end{array}$ \\
\hline $\begin{array}{l}\text { Embolismo } \\
\text { arterial }\end{array}$ & Escarlatina estafilocócica & Ectima gangrenoso \\
\hline $\begin{array}{l}\text { Síndrome } \\
\text { compartimental }\end{array}$ & Síndrome de Sézary & Pioderma gangrenoso \\
\hline $\begin{array}{l}\text { Hematomas y } \\
\text { equimosis de } \\
\text { partes blandas }\end{array}$ & $\begin{array}{l}\text { Eritema multiforme, síndrome de } \\
\text { Stevens-Johnson, necrólisis epidérmica } \\
\text { tóxica por múltiples causas }\end{array}$ & $\begin{array}{l}\text { Abscesos de partes blandas } \\
\text { con necrosis cutánea }\end{array}$ \\
\hline Traumatismos & $\begin{array}{l}\text { Síndrome de la piel escalada } \\
\text { estafilocócica }\end{array}$ & Celulitis infecciosa \\
\hline Coagulopatías & $\begin{array}{l}\text { En niños: Enfermedad de Kawasaki, } \\
\text { enfermedad de Ritter o síndrome de la } \\
\text { piel escalada estafilocócica }\end{array}$ & Mucormicosis \\
\hline
\end{tabular}

El tratamiento debe ser rápido y requiere de un enfoque multidisciplinario. Se debe efectuar el control local de la infección mediante cirugía, soporte hemodinámico y un tratamiento antibiótico específico.

Es fundamental una exploración quirúrgica precoz y agresiva. La cirugía abarca desde procedimientos diagnósticos mediante la revisión del tejido celular subcutáneo, fascia y músculo a través de una pequeña incisión, obteniendo una muestra en fresco para análisis, hasta una cirugía de desbridamiento cuyo objetivo es eliminar tejido desvitalizado., ${ }^{1,3}$ En el caso de nuestro paciente no se pudo llevar a cabo una intervención quirúrgica adecuada debido a que se encontraba inestable hemodinamicamente.

El soporte hemodinámico incluye el aporte de líquido intravenosos, así como el uso de aminas vasoactivas. La hemodiálisis puede ser necesaria en caso de disfunción renal y la ventilación mecánica invasiva en caso de distrés respiratorio. 
El esquema antimicrobiano empírico recomendado como primera línea ante la sospecha de infección por EGA es la asociación de Penicilina G benzatínica (3 millones de UI cada 4 horas) y Clindamicina (600 a 900 mg cada 6 a 8 horas). ${ }^{13}$

Otras modalidades terapéuticas en desarrollo incluyen el uso de gammaglobulina por vía intravenosa y oxígeno hiperbárico preoperatorio. ${ }^{4}$

El caso presentado muestra que a pesar de la sospecha clínica temprana, la adecuada selección del antibiótico, el desbridamiento quirúrgico y las medidas de soporte hemodinámico, es una patología de rápida progresión a shock y fallo multiorgánico.

\section{Bibliografía}

1. Rodríguez Lorenzo A, Midón Míguez J, Martelo Villar F. Síndrome del shock tóxico estreptocócico tras fascitis necrotizante por estreptococo pyogenes. Cir. Plást. Iberolatinoam. 2007; 33(4):257-262.

2. Kojic $M$, Mikic $D$, Nozic $D$, Rakonjac $B$. Streptoccocal Necrotizing Fascitis with Toxic Shock Syndrome and Rapid Fatal Outcome. Srp Arh Celok Lek. 2015; 143(7-8): 476-479.

3. Ayala Gaytán JJ, Guajardo Lara CE, Valdovinos Chávez SB. Fascitis necrotizante y choque tóxico en infección por estreptococo del grupo $A$. Rev Med Inst Mex Seguro Soc. 2011; 49(4):425-432.

4. Lipworth $A D$, Saavedra $A P$, Weinberg $A N$, Johnson RA. Infecciones necrosantes del tejido blando: fascitis necrosante, celulitis gangrenosa $y$ mionecrosis. En Goldsmith LA, Katz SI, Gilchrest $B A$, Paller AS, Leffell DJ, Wolff $K$, directores. Fiztpatrick Dermatología en Clínica Médica. Vol 2. 8a edición. España: Editorial Médica Panamericana, 2012, p 2169-2177.

5. Lancerotto L, Tocco I, Salmaso R, Vindigni V, Bassetto F. Necrotizing fasciitis: Classification, diagnosis, and management. J Trauma. 2012; 72:560-566.

6. Al Shukry S, Ommen J. Necrotizing Fasciitis. Report of ten cases and review of recent literature. Journal of Medicine and Life. 2013; 6(2):189-194.
7. Sun X, Xie T. Management of Necrotizing Fasciitis and Its Surgical Aspects. The International Journal of Lower Extremity Wounds. 2015;14(4):328-334.

8. Rodríguez Lorenzo A, Martelo Villar F. Fallo renal agudo en varón joven con celulitis en extremidad inferior. An Med Interna. 2008;25:291293.

9. Maya SP, Dualde Beltrán D, Lemercier P, Leiva Salinas C. Necrotizing fascitis: an urgent diagnosis. Skeletal Radiol.2014; 43:577-589.

10. Stevens DL. Streptococcal Toxic-Shock Syndrome: Spectrum of Disease, Pathogenesis, and New Concepts in Treatment. Emerging Infectious Diseases. 1995; 1(3):69-76.

11. Parra Caballero P, Pérez Esteban S, Patiño Ruiz ME, Castañeda Sanz S, García Vadillo JA. Actualización en fascitis necrotizante. Semin Fund Esp Reumatol. 2012; 13(2):41-48.

12. Torrabadella de Reynoso $P$, Misis del Campo $M$, Güell Peris X. Fascitis Necrosante. Piel. 1999; 13(1):1827.

13. Mendoza Ramírez OE, Medina Lombo RA. Fascitis necrosante. Repertorio de Medicina $y$ Cirugía. 2007; 16(1):7-14 